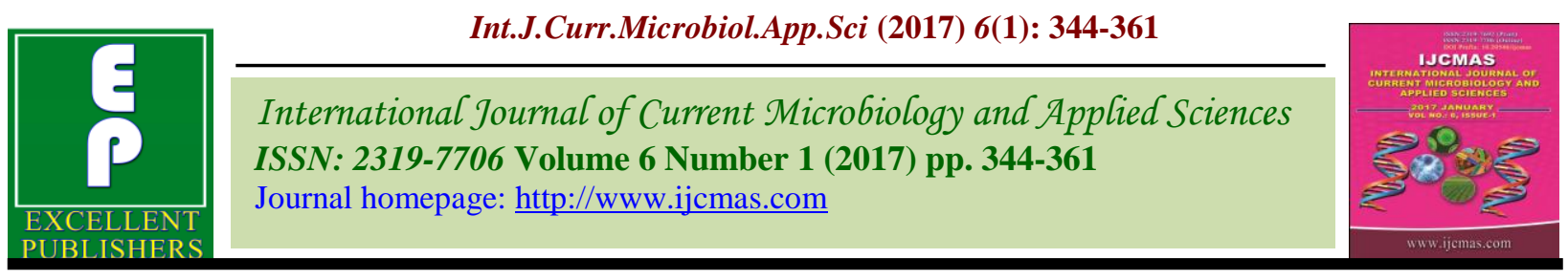

Original Research Article

http://dx.doi.org/10.20546/ijcmas.2017.601.042

\title{
A Study of Microalbuminuria in Coronary Artery Disease among Non-Diabetic Individuals
}

\author{
R.L. Sunjay Pradhep*, N. Janakiram, Vivek Paul Benjamin and S. Natarajan \\ Department of General Medicine, Meenakshi Medical College and Research Institute, \\ Enathur, Kanchipuram - 631552, India \\ *Corresponding author
}

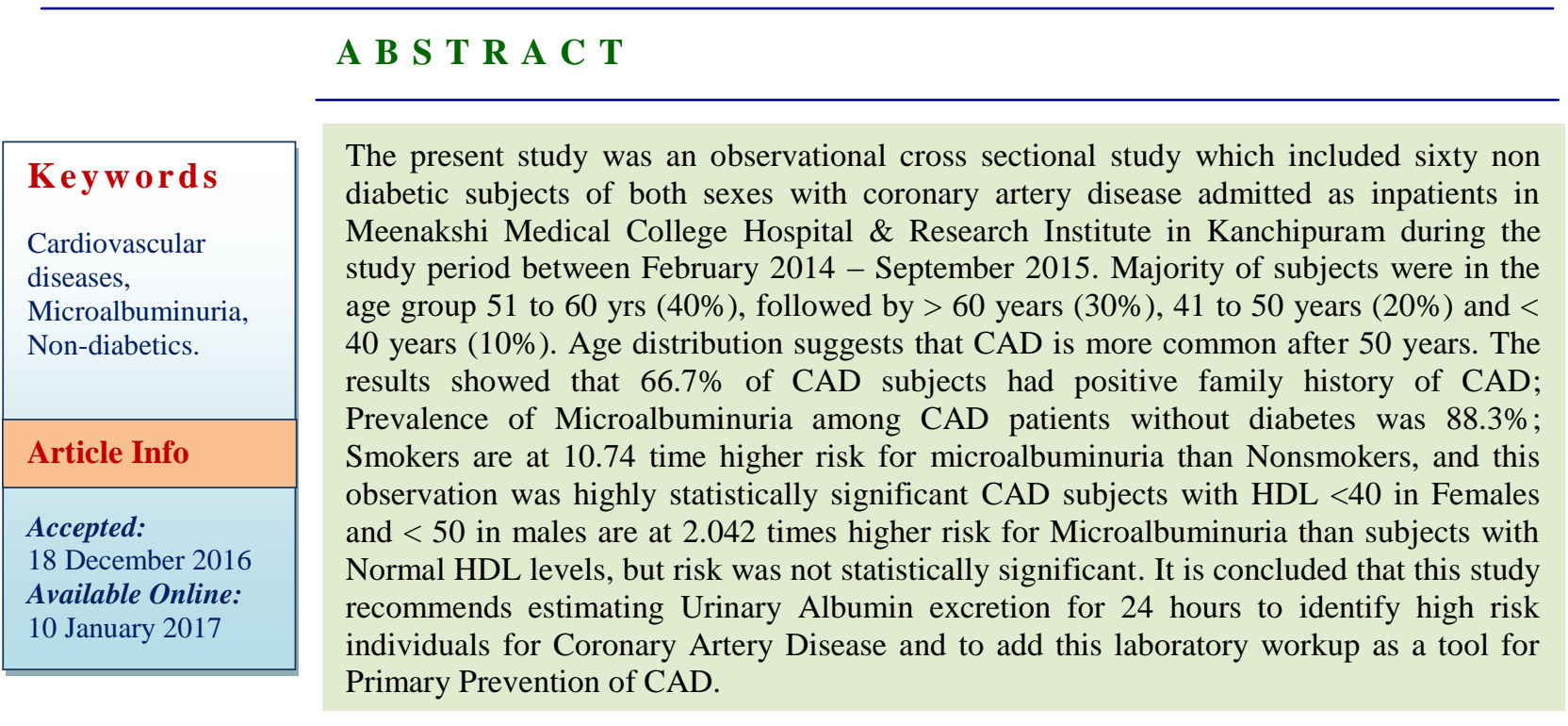

\section{Introduction}

Cardiovascular diseases are the most prevalent serious disorders among the industrialized nations and are rapidly growing among developing nations including India. Cardiovascular disease is responsible for 12 million deaths per year globally and is the commonest cause of death (Harrison's principles of internal medicine). Previously considered a disease of rich, in the last thirty years Coronary Artery Disease (CAD) has reduced in incidence and prevalence in western nations but is increasing rapidly to become epidemic proportions in developing nations. Indians whether living in India or abroad have a higher incidence of CAD compared to other ethnic groups (API text book of medicine 10th edition).

Ischemic heart disease is a condition in which there is an inadequate supply of blood and oxygen to a portion of myocardium. It typically occurs when there is imbalance between myocardial oxygen supply and demand. The most common cause of myocardial ischemia is atherosclerotic disease of an epicardial coronary artery sufficient to 
cause a regional reduction in myocardial blood flow and inadequate perfusion of the myocardium supplied by the involved coronary artery (API text book of medicine 10th edition).

By the year 2020, cardiovascular diseases could be the most important cause of mortality in India. The prevalence of coronary artery disease in India increased from $1 \%$ in 1960 to $9.7 \%$ in 1995 in urban populations, and in rural populations it has almost doubled in the last decade. There is an epidemiological transition from infective to degenerative diseases, increases in the prevalence of cardiovascular risk factors, and ageing of the population, which eventually leads to an increase in the absolute number of people with coronary artery disease and increased health awareness and demand for health care facilities (API text book of medicine 10th edition).

While incidence of CAD has reduced by $50 \%$ in the west, in India it has doubled in the last 25 years. The prevalence of CAD in the years 1960, 1980, 1990 and 2000 progressively increased $(2 \%, 4 \%$ to $6 \%, 9.5 \%$ and $10 \%$ to $15 \%$ respectively). In rural India, the CAD prevalence increased two-fold from $2 \%$ to 4 $\%$; in urban India the increase was three-fold from $3.45 \%$ to $9.45 \%$. In $199025 \%$ deaths in India were attributable to cardiovascular disease compared to $9 \%$ due to diarrhoeal disease, $12 \%$ due to respiratory infections and $5 \%$ due to tuberculosis (API text book of medicine 10 th edition).

There is a steep increase in prevalence of coronary artery disease in urban areas in India. Since the pioneering work of the Framingham study, many prospective and clinical studies have identified a series of independent risk factors for ischemic heart disease among which age, male gender, smoking, hypertension, and diabetes mellitus, a positive family history of premature atherosclerotic disease, hypercholesterolemia, hyper triglyceridemia and low HDL cholesterol are considered as classical risk factors.

The interest in improving cardiovascular risk assessment, resulting from a better understanding of the pathogenesis of atherosclerosis and identification of new targets for anti-atherosclerotic drug therapy has stimulated the search for novel risk factors (Hillege et al., 2001).

One such novel risk factor is microalbuminuria which has emerged as an independent and robust risk factor. Microalbuminuria is a well-accepted marker for micro and macro vascular damage in patients with diabetes mellitus. However more and more evidence is accumulating that microalbuminuria is an important cardiovascular risk factor even in the general population (Diercks et al., 2000).

The urinary protein called albumin is increasingly recognized as the earliest sign of vascular damage in both the kidney and the heart. The phenomenon of albuminuria has been recognized for more than 200 years, and its association with kidney disease dates to the epochal insights of Richard Bright in 1827. Microalbuminuria is defined as urinary albumin excretion of 30 - $300 \mathrm{mg} / \mathrm{day}$, or 20$200 \mu \mathrm{g} / \mathrm{min}$.

Microalbuminuria may be a marker of generalized vascular disease, with arterial endothelial dysfunction being involved in the pathogenesis of atherothrombotic vascular disease. The exact pathophysiology regarding how microalbuminuria contributes to or accelerates the atherosclerotic process is uncertain. The current understanding, however suggests that mechanisms of vascular injury associated with 
microalbuminuria are different between those without diabetes who also have hypertension (Pedrinelli et al., 1994).

It is of interest that presence of microalbuminuria may even precede manifest diabetes and hypertension. Microalbuminuria may be considered one of the earliest manifestations of the insulin resistance syndrome. Indeed, it has been shown that the prevalence of microalbuminuria increases according to the number of components of the metabolic syndrome present. This raises doubt whether we should limit our screening strategies to those with known risk factors or preferably should screen the general population.

The importance of microalbuminuria as an independent predictor of progressive renal disease and cardiovascular mortality was thereafter realized in a number of prospective and epidemiological studies particularly in patients with diabetes and hypertension. In adults, the link between microalbuminuria, cardiovascular disease, and progressive renal disease is now well established in patients with systemic diseases including diabetes mellitus. Interestingly, microalbuminuria has also emerged to be an important risk factor for the development of cardiovascular disease, and all-cause mortality in the general population.

Arterial hypertension is, in some patients, associated with a subclinical increase of the albumin excretion in the urine (microalbuminuria), in spite of preserved renal function. In hypertensive patients microalbuminuria has often been related to an excess of atherosclerotic cardiovascular disease, which is more frequent in the hypertensive population, and to an increased level of atherosclerotic risk markers (Pedrinelli et al., 1994).
In a prospective population based study of hypertensives, that reports an independent predictive effect of microalbuminuria in the development of ischemic heart disease. Among hypertensive subjects screened within another Danish population study, the Copenhagen city heart study, we have described a cross sectional relation between urinary albumin excretion and IHD, confirming a previous report by another study done by Agrawal et al., Bigazzi et al., analyzed data obtained from retrospectively selected hospital population of 141 hypertensives. They observed an unadjusted relative risk of 2.4 for the development of ischemic heart disease during a 7 year follow up among microalbuminuria patients.

In a study done in Danish medical research council and Danish heart foundation concluded that microalbuminuria is a marker of generalized vascular dysfunction (STENO HYPOTHESIS), elevated urinary albumin has also been demonstrated in non diabetic individuals and it has to be found associated with elevated blood pressure, dyslipidemia and high plasma insulin levels (obesity). Hypertension and dyslipidemia are both wellestablished risk factors for the development of cardiovascular disease.

In a study "Albuminuria and risk of cardiovascular events, death and heart failure in diabetic and non-diabetic individuals" Department of medicine, Hamilton Ontario where results indicate that any degree of albuminuria is a risk factor for cardiovascular events in individuals with or without Diabetes mellitus; The risk increases with Albumin creatinine ratio, starting well below the cut off value of microalbuminuria. Screening for albuminuria identifies people at high risk for cardiovascular events.

Microalbuminuria is a cardinal sign and a warning to the physician about the problems 
of vascular wall. It is a reversible condition so that the person by adopting control measures to reverse MAU like losing weight by increased physical activity and diet changes can be safeguarded from the dreaded complications of cardiovascular and renal diseases in future life.

Microalbuminuria is an important cardiovascular and mortality risk factor, irrespective of diabetes or hypertension. It increases the relative risk of major cardiovascular events, even after adjustment for other cardiovascular risk factors. Risk increases with the albumin-to-creatinine ratio, starting well below the microalbuminuria cutoff. Multivariate analysis has shown that left ventricular (LV) hypertrophy is associated with a 1.6-fold higher prevalence of microalbuminuria, independent of age, systolic or diastolic blood pressure (BP), diabetes, gender, race, serum creatinine, or smoking status (Wachtell et al., 2002).

Thus, microalbuminuria, an integrated marker of cardiovascular risk, may be particularly effective to identify patients at higher absolute risk in whom preventive treatment will be more beneficial than patients with a lower absolute risk. Reduction of subclinical albuminuria as such may also represent a clinically relevant end-point worth being actively pursued by pharmacological treatment. Although no evidence is available in this regard, the antiproteinuric effect of ACE inhibitors or angiotensin II receptor blockers paralleled a better renal and cardiovascular prognosis in hypertensive patients with renal failure, either diabetic or not. The issue reminds, to some extent, the debate about cardiac hypertrophy, in which earlier hypotheses were a long time being proven, although, hopefully, we will have to wait less time to get an answer about nondiabetic microalbuminuria (Knight et al., 2003).
It was recently suggested that smoking, in addition to its well-known cardiovascular consequences, could accelerate the progression of renal diseases. However, our understanding of the acute effects and long-term influence of smoking on renal hemodynamics and albuminuria is poor, and many questions remain unanswered. Smoking was associated with excessive urinary albumin excretion in hypertensive subjects. In fact the prevalence of microalbuminuria was two-fold higher in lean, never treated hypertensive smokers than in non-smokers. Similar results were also reported in normotensive subjects. Of note, the most important determinant of microalbuminuria is usually arterial pressure, especially when ambulatory arterial pressure is used.

Cigarette smoking causes a nicotine-induced stimulation of the sympathetic nervous system (i.e. adrenaline and nor adrenaline release) that acutely increases arterial pressure and heart rate. The implication of the sympathetic nervous system in the acute renal vasoconstriction observed following nicotine gum administration was unlikely since arterial pressure and heart rate rose in both smokers and non-smokers, whereas glomerular filtration rate and effective renal plasma flow decreased only in non-smokers. Nevertheless, the sympathetic nervous system may play a role in the chronic renal effects of smoking.

Similar to type 1 and 2 Diabetics, nondiabetic smokers, hypertensive or not, tend to excrete more albumin. The first report by Gosling et al., confirmed later on by other investigators, has recently been established by the Gubbio, HOPE and PREVEND studies, all showing an association independent of coexisting diabetes and hypertension. The finding is in line with the hypothesis of microalbuminuria as an expression of diffuse endothelial dysfunction, since smoke damages endothelial function, induces a chronic 
subclinical inflammatory state and promotes atherosclerotic vascular disease, and may expose to higher risk of morbid events when coexisting with elevated urinary albumin excretion (Gerstein et al., 2000).

Microalbuminuria seems to reflect a state of patho-physiologic vascular dysfunction that makes an individual susceptible to organ damage. High levels of albuminuria may already be found in young children and reflect a normal physiologic variation in endothelial function associated with Cardiovascular and Renal risk at later age. Intervention strategies aimed at repairing this vascular function could be very useful not only in secondary but also in primary prevention. Albumin excretion levels may represent the primary marker for success of such therapies.

The main aim and objectives of this study includes, to estimate the prevalence of Microalbuminuria in non-diabetic patients with Coronary Artery Disease (CAD). And also study the association between Microalbuminuria and other risk factors for Coronary Artery Disease.

\section{Materials and Methods}

Study Design

Observational cross sectional study

\section{Study Subjects}

Sixty non diabetic subjects of both sexes with coronary artery disease admitted as inpatients in Meenakshi Medical College Hospital \& Research Institute in Kanchipuram during the study period between February 2014 September 2015 were included.

\section{Inclusion Criteria}

- CAD patients based on Coronary Angiogram
- Both sexes

- Non-diabetic patients

\section{Exclusion Criteria}

- Diabetes Mellitus

- Congestive cardiac failure as presentation

- Female patients with vaginal discharge

- Urine showing

○ Macroalbuminuria (dipstick positive)

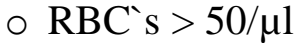

○ Leucocytes $>75 / \mu 1$

\section{Sampling Method}

Non-diabetic, CAD patients were included till sample size is achieved from February 2014 September 2015.

The patients were given a container for collection of urine over 24 hours which was sent for the estimation of Albumin level by immunoturbidimetry method.

In this study, only in patients who were diagnosed to have CAD by Coronary angiogram using Philips - Allura Xper FD10 Cardiovascular X-ray system in our Cath lab were selected.

\section{Method of Study}

After getting ethical clearance from the Institutional Ethical Committee, study was started from February 2014. Patients who fit in the inclusion and exclusion criteria were explained about the study and a written consent was obtained from those who were willing to participate in the study. All the needed information was collected using a pre tested semi structured questionnaire. Investigations were carried out in each case. Study was done with reference to risk factors like age, gender, smoking, obesity, hypertension and dyslipidemia. 


\section{Statistical Methods}

Data was entered into Microsoft excel data sheet and was analyzed using SPSS 22 version software. Categorical data was represented in the form of Frequencies and proportions. Chi-square was used as test of significance. Continuous data was represented as mean and standard deviation. Independent t-test was used as test of significance to identify the mean difference between two groups. p-value $<0.05$ was considered as statistically significant.

\section{Results and Discussion}

Sixty cases of CAD without Diabetes mellitus were included in this study.

Albuminuria has been identified as a lifethreatening renal and cardiovascular risk profile. This important diagnostic parameter can not only predict renal or concurrent renal and cardiovascular adverse events in high-risk patients, such as diabetics and hypertensive patients (ranging from 10 to $40 \%$ ), but can also be frequently found in seemingly healthy subjects, with an overall prevalence of 5 to $7 \%$ in normal individuals.

In spite of the observed link between microalbuminuria and cardiovascular disorders, its pathophysiological mechanisms responsible for progression of cardiac dysfunction or heart failure have been largely unknown.

Majority of subjects were in the age group 51 to $60 \mathrm{yrs}(40 \%)$, followed by $>60$ years $(30 \%), 41$ to 50 years $(20 \%)$ and $<40$ years $(10 \%)$. Age distribution suggests that CAD is more common after 50 years. There was significant difference in proportions (Table $1)$. In the present study, majority of subjects were males $(78.3 \%)$ and $21.7 \%$ were females. This observation was statistically significant (Table 2).

Table 3 reveals that $66.7 \%$ of CAD subjects had positive family history of CAD. This observation was statistically significant. As observed from Table 4, 58.3\% had history of smoking, there was no significant difference in proportions.

Table.1 Age distribution of subjects

\begin{tabular}{|c|c|c|c|}
\hline & & Frequency & $\%$ \\
\hline \multirow{5}{*}{ Age } & $<40$ years & 6 & $10.0 \%$ \\
\hline & 41 to 50 years & 12 & $20.0 \%$ \\
\hline & 51 to 60 years & 24 & $40.0 \%$ \\
\hline & $>60$ years & 18 & $30.0 \%$ \\
\hline & Total & 60 & $100.0 \%$ \\
\hline \multicolumn{2}{|c|}{ Mean Age } & \multicolumn{2}{|c|}{$55.13 \pm 9.95$ years } \\
\hline
\end{tabular}

Table. 2 Gender Distribution of subjects

\begin{tabular}{|c|c|c|c|}
\hline \multicolumn{2}{|c|}{} & Frequency & \% \\
\hline \multirow{3}{*}{ Gender } & Female & 13 & 21.7 \\
\cline { 2 - 4 } & Male & 47 & 78.3 \\
\cline { 2 - 4 } & Total & 60 & 100.0 \\
\hline
\end{tabular}

$\chi^{2}=18.15, \mathrm{df}=1, \mathrm{p}<0.0001^{*}$ 
Table.3 Family History of CAD in Subjects

\begin{tabular}{|c|c|c|c|}
\hline \multicolumn{2}{|c|}{} & Frequency & Percent \\
\hline \multirow{3}{*}{ Family H/o CAD } & No & 20 & 33.3 \\
\cline { 2 - 4 } & Yes & 40 & 66.7 \\
\cline { 2 - 4 } & Total & 60 & 100.0 \\
\hline
\end{tabular}

$\chi 2=6.017, \mathrm{df}=1, \mathrm{p}=0.0142 *$

Table.4 Smoking History in subjects

\begin{tabular}{|c|c|c|c|}
\hline \multicolumn{2}{|c|}{} & Frequency & Percent \\
\hline \multirow{3}{*}{ Smoking } & No & 25 & 41.7 \\
\cline { 2 - 4 } & Yes & 35 & 58.3 \\
\cline { 2 - 4 } & Total & 60 & 100.0 \\
\hline
\end{tabular}

$\chi 2=1.350, \mathrm{df}=1, \mathrm{p}=0.2453$

Majority of CAD subjects were overweight $(76.7 \%)$ and $18.3 \%$ were obese. This observation in difference in proportions among CAD subjects was statistically significant (Table 5).

The results presented in Table 6 show $61.7 \%$ of subjects with hypertension and $38.3 \%$ without hypertension. This observation was not statistically significant.

Prevalence of Microalbuminuria among CAD patients without diabetes was $88.3 \%$. This observation was statistically significant. Mean Microalbumin levels was $56.9 \pm 30.4 \mathrm{mg}$ (Table 7).

Table.5 Distribution of subjects according to BMI

\begin{tabular}{|c|c|c|c|}
\hline & & Frequency & Percent \\
\hline \multirow{4}{*}{ BMI } & 18.5 to 22.9 Normal & 3 & 5.0 \\
\hline & 23 to 27.5 Overweight & 46 & 76.7 \\
\hline & $>27.5$ Obese & 11 & 18.3 \\
\hline & Total & 60 & 100.0 \\
\hline \multicolumn{2}{|r|}{ Mean BMI } & \multicolumn{2}{|c|}{$25.89 \pm 2.24$} \\
\hline
\end{tabular}

Table.6 Distribution of Subjects according to History of Hypertension

\begin{tabular}{|c|c|c|c|}
\hline \multicolumn{2}{|c|}{} & Frequency & Percent \\
\hline \multirow{3}{*}{ HTN } & No & 23 & 38.3 \\
\cline { 2 - 4 } & Yes & 37 & 61.7 \\
\cline { 2 - 4 } & Total & 60 & 100.0 \\
\hline \multicolumn{3}{|c|}{$\chi 2=2.817, \mathrm{df}=1, \mathrm{p}=0.093$}
\end{tabular}


Table.7 Prevalence of Micro albuminuria among CAD subjects

\begin{tabular}{|c|c|c|c|}
\hline \multicolumn{2}{|c|}{ Micro albuminuria } & Frequency & \% \\
\cline { 2 - 4 } & Absent (<30 mg) & 7 & $11.7 \%$ \\
\hline \multicolumn{2}{|c|}{ Mean Albumin Levels $(30$ to $300 \mathrm{mg})$} & 53 & $88.3 \%$ \\
\hline \multicolumn{2}{|c|}{$56.9 \pm 30.4$} \\
\hline
\end{tabular}

$\chi 2=33.75, \mathrm{df}=1, \mathrm{p}<0.001^{*}$

Table. 8 shows the various quantitative variables considered in the present study. The mean Microalbuminuria was found to be 56.9.

There was no significant association between Age and Microalbuminuria among CAD subjects in the study (Table 9). Odds ratio was 2.83 , i.e. $>50$ years are at 2.83 times higher risk for Microalbuminuria than $<50$ years, but risk was not statistically significant. As observed from the results shown in Table 10 that there was no significant association between Gender and Microalbuminuria among CAD subjects in the study. Odds ratio was 3.225 , i.e., Males are at 3.225 time higher risk for Microalbuminuria than Females, but the risk was not statistically significant (Table 10). There was no significant association between Family H/O CAD and Micro albuminuria among CAD subjects in the study (Table 11). Odds ratio was 3.083, i.e. CAD subjects with Family H/O CAD are at 3.083 time higher risk for Micro albuminuria than without Family H/O CAD, but risk was not statistically significant.

In the present study, there was a significant association between Smoking and Microalbuminuria among CAD subjects. Odds ratio was 10.74 , i.e. Smokers are at 10.74 time higher risk for icroalbuminuria than Nonsmokers, and this observation was highly statistically significant (Table 12).

There was no significant association between BMI and Microalbuminuria among CAD subjects in the study (Table 13). Odds ratio was 1.19 , i.e. CAD subjects with BMI > 23 are at 1.19 time higher risk for Microalbuminuria than subjects with BMI $<23$, but risk was not statistically significant.

Table.8 Mean and Standard Deviation of Quantitative Variables in the Study

\begin{tabular}{|l|c|c|}
\hline \multicolumn{1}{|c|}{ Parameters } & Mean & SD \\
\hline Height & 164.63 & 6.57 \\
\hline Weight & 70.18 & 5.91 \\
\hline BMI (Body Mass Index) & 25.90 & 2.24 \\
\hline SBP (Systolic blood pressure) & 144.77 & 16.75 \\
\hline DBP (Diastolic blood pressure) & 89.53 & 10.27 \\
\hline FBS (Fasting Blood Sugar) & 94.27 & 9.19 \\
\hline Total Cholesterol & 164.43 & 39.19 \\
\hline TG (Triglyceride) & 130.28 & 73.61 \\
\hline HDL (High Density Lipoprotein) & 35.82 & 8.32 \\
\hline LDL (Low density Lipoprotein) & 95.82 & 41.19 \\
\hline Microalbuminuria & 56.90 & 30.43 \\
\hline
\end{tabular}


Table.9 Association between Microalbuminuria and Age in CAD subjects

\begin{tabular}{|c|c|c|c|c|c|c|c|}
\hline \multirow{3}{*}{\multicolumn{2}{|c|}{ Parameters }} & \multicolumn{4}{|c|}{ Microalbuminuria } & \multirow{3}{*}{$P$ value } & \multirow{3}{*}{ Odds Ratio } \\
\hline & & \multicolumn{2}{|c|}{ Absent (<30 mg) } & \multicolumn{2}{|c|}{ Present $(30$ to $300 \mathrm{mg}$ ) } & & \\
\hline & & Frequency & $\%$ & Frequency & $\%$ & & \\
\hline \multirow{4}{*}{ Age } & $<40$ years & 0 & $0.0 \%$ & 6 & $11.3 \%$ & \multirow{4}{*}{0.317} & \multirow{4}{*}{$\begin{array}{c}2.83(0.3158 \\
25.42)\end{array}$} \\
\hline & 41 to 50 years & 1 & $14.3 \%$ & 11 & $20.8 \%$ & & \\
\hline & 51 to 60 years & 5 & $71.4 \%$ & 19 & $35.8 \%$ & & \\
\hline & $>60$ years & 1 & $14.3 \%$ & 17 & $32.1 \%$ & & \\
\hline
\end{tabular}

Table.10 Association between Microalbuminuria and Gender in CAD subjects.

\begin{tabular}{|c|c|c|c|c|c|c|c|}
\hline \multirow{3}{*}{\multicolumn{2}{|c|}{ Parameters }} & \multicolumn{4}{|c|}{ Microalbuminuria } & \multirow{3}{*}{ P value } & \multirow{3}{*}{ Odds Ratio } \\
\hline & & \multicolumn{2}{|c|}{ Absent (<30 mg) } & \multicolumn{2}{|c|}{ Present (30 to $300 \mathrm{mg})$} & & \\
\hline & & Frequency & $\%$ & Frequency & $\%$ & & \\
\hline \multirow{2}{*}{ Gender } & Female & 3 & $42.9 \%$ & 10 & $18.9 \%$ & \multirow{2}{*}{0.148} & \multirow{2}{*}{$\begin{array}{c}3.225 \\
(0.621, \\
16.75)\end{array}$} \\
\hline & Male & 4 & $57.1 \%$ & 43 & $81.1 \%$ & & \\
\hline
\end{tabular}

Table.11 Association between Microalbuminuria and Family H/O CAD in CAD subjects.

\begin{tabular}{|c|c|c|c|c|c|c|c|}
\hline \multirow{3}{*}{\multicolumn{2}{|c|}{ Parameters }} & \multicolumn{4}{|c|}{ Microalbuminuria } & \multirow{3}{*}{$P$ value } & \multirow{3}{*}{ Odds Ratio } \\
\hline & & \multicolumn{2}{|c|}{ Absent (<30 mg) } & \multicolumn{2}{|c|}{$\begin{array}{c}\text { Present } \\
\text { (30 to } 300 \mathrm{mg})\end{array}$} & & \\
\hline & & Frequency & $\%$ & Frequency & $\%$ & & \\
\hline \multirow[b]{2}{*}{ Family H/O CAD } & No & 4 & $57.1 \%$ & 16 & $30.2 \%$ & \multirow[b]{2}{*}{0.155} & \multirow{2}{*}{$\begin{array}{c}3.083 \\
(0.6178, \\
15.39)\end{array}$} \\
\hline & Yes & 3 & $42.9 \%$ & 37 & $69.8 \%$ & & \\
\hline
\end{tabular}

Table.12 Association between Microalbuminuria and Smoking in CAD subjects.

\begin{tabular}{|c|c|c|c|c|c|c|c|}
\hline \multirow{3}{*}{\multicolumn{2}{|c|}{ Parameters }} & \multicolumn{4}{|c|}{ Microalbuminuria } & \multirow{3}{*}{$P$ value } & \multirow{3}{*}{ Odds Ratio } \\
\hline & & \multicolumn{2}{|c|}{$\begin{array}{c}\text { Absent } \\
(<30 \mathrm{mg})\end{array}$} & \multicolumn{2}{|c|}{$\begin{array}{c}\text { Present } \\
\text { (30 to } 300 \mathrm{mg} \text { ) }\end{array}$} & & \\
\hline & & Frequency & $\%$ & Frequency & $\%$ & & \\
\hline \multirow{2}{*}{ Smoking } & Yes & 1 & $14.3 \%$ & 34 & $64.2 \%$ & \multirow{2}{*}{$0.012 * *$} & \multirow{2}{*}{$\begin{array}{c}10.74 *(1.202 \\
95.94)\end{array}$} \\
\hline & No & 6 & $85.7 \%$ & 19 & $35.8 \%$ & & \\
\hline
\end{tabular}


Table.13 Association between Microalbuminuria and BMI in CAD subjects

\begin{tabular}{|c|c|c|c|c|c|c|c|}
\hline \multirow{3}{*}{\multicolumn{2}{|c|}{ Parameters }} & \multicolumn{4}{|c|}{ Microalbuminuria } & \multirow{3}{*}{ P value } & \multirow{3}{*}{$\begin{array}{l}\text { Odds } \\
\text { Ratio }\end{array}$} \\
\hline & & \multicolumn{2}{|c|}{$\begin{array}{c}\text { Absent } \\
(<30 \text { mg })\end{array}$} & \multicolumn{2}{|c|}{$\begin{array}{c}\text { Present } \\
\text { (30 to } 300 \mathrm{mg} \text { ) }\end{array}$} & & \\
\hline & & Frequency & $\%$ & Frequency & $\%$ & & \\
\hline \multirow{4}{*}{ BMI } & $<18.5$ Underweight & 0 & $0.0 \%$ & 0 & $0.0 \%$ & \multirow{4}{*}{0.759} & \multirow{4}{*}{$\begin{array}{c}1.19 \\
(0.053, \\
26.33)\end{array}$} \\
\hline & 18.5 to 22.9 Normal & 0 & $0.0 \%$ & 3 & $5.7 \%$ & & \\
\hline & 23 to 27.5 Overweight & 6 & $85.7 \%$ & 40 & $75.5 \%$ & & \\
\hline & $>27.5$ Obese & 1 & $14.3 \%$ & 10 & $18.9 \%$ & & \\
\hline
\end{tabular}

The association between Hypertension and Microalbuminuria among CAD subjects in the study was observed to be statistically significant. Odds ratio was 32.38 , i.e. Hypertensive subjects are at 32.38 time higher risk for Microalbuminuria than Non hypertensive subjects, and this observation was highly statistically significant (Table 14).

The results of the present research indicated in Table 15 reveal that there was no significant association between Total cholesterol and Microalbuminuria among
CAD subjects. Odds ratio was 0.44 , i.e. CAD subjects with Total cholesterol $<200 \mathrm{mg} / \mathrm{dl}$ were protected from Microalbuminuria than subjects with Total cholesterol > 200mg/dl, but it was not statistically significant.

There was no significant association between Triglyceride and Microalbuminuria among CAD subjects in the study. Odds ratio was 2.83, i.e. CAD subjects with $\mathrm{TG}>150 \mathrm{mg} / \mathrm{dl}$ are at 2.83 times higher risk for Microalbuminuria than subjects with $\mathrm{TG}<150 \mathrm{mg} / \mathrm{sl}$, but risk was not statistically significant (Table 15).

Table.14 Association between Microalbuminuria and Hypertension in CAD subjects

\begin{tabular}{|c|c|c|c|c|c|c|c|}
\hline \multirow{3}{*}{\multicolumn{2}{|c|}{ Parameters }} & \multicolumn{4}{|c|}{ Microalbuminuria } & \multirow{3}{*}{ P value } & \multirow{3}{*}{ Odds Ratio } \\
\hline & & \multicolumn{2}{|c|}{$\begin{array}{l}\text { Absent } \\
(<30 \text { mg })\end{array}$} & \multicolumn{2}{|c|}{$\begin{array}{c}\text { Present } \\
\text { (30 to } 300 \mathrm{mg} \text { ) }\end{array}$} & & \\
\hline & & Frequency & $\%$ & Frequency & $\%$ & & \\
\hline \multirow{2}{*}{ HTN } & Yes & 0 & $0.0 \%$ & 37 & $69.8 \%$ & \multirow{2}{*}{$<0.001 *$} & \multirow{2}{*}{$\begin{array}{l}32.38 * \\
(1.732, \\
605.2)\end{array}$} \\
\hline & No & 7 & $100.0 \%$ & 16 & $30.2 \%$ & & \\
\hline
\end{tabular}

Table.15 Association between Microalbuminuria and Total Cholesterol in CAD subjects

\begin{tabular}{|c|c|c|c|c|c|c|c|}
\hline \multirow{3}{*}{\multicolumn{2}{|c|}{ Parameters }} & \multicolumn{4}{|c|}{ Microalbuminuria } & \multirow{3}{*}{$P$ value } & \multirow{3}{*}{$\begin{array}{l}\text { Odds } \\
\text { ratio }\end{array}$} \\
\hline & & \multicolumn{2}{|c|}{$\begin{array}{c}\text { Absent } \\
(<30 \mathrm{mg})\end{array}$} & \multicolumn{2}{|c|}{$\begin{array}{c}\text { Present } \\
\text { (30 to } 300 \mathrm{mg} \text { ) }\end{array}$} & & \\
\hline & & Frequency & $\%$ & Frequency & $\%$ & & \\
\hline \multirow{2}{*}{$\begin{array}{c}\text { Total } \\
\text { Cholesterol }\end{array}$} & $\begin{array}{l}<200 \\
\mathrm{mg} / \mathrm{dl}\end{array}$ & 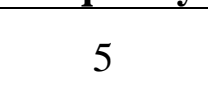 & $71.4 \%$ & 45 & $84.9 \%$ & \multirow{2}{*}{0.369} & \multirow{2}{*}{$\begin{array}{c}0.44 \\
(0.07, \\
2.69)\end{array}$} \\
\hline & $\begin{array}{l}>200 \\
\mathrm{mg} / \mathrm{dl}\end{array}$ & 2 & $28.6 \%$ & 8 & $15.1 \%$ & & \\
\hline
\end{tabular}


Table.16 Association between Microalbuminuria and Triglyceride in CAD subjects

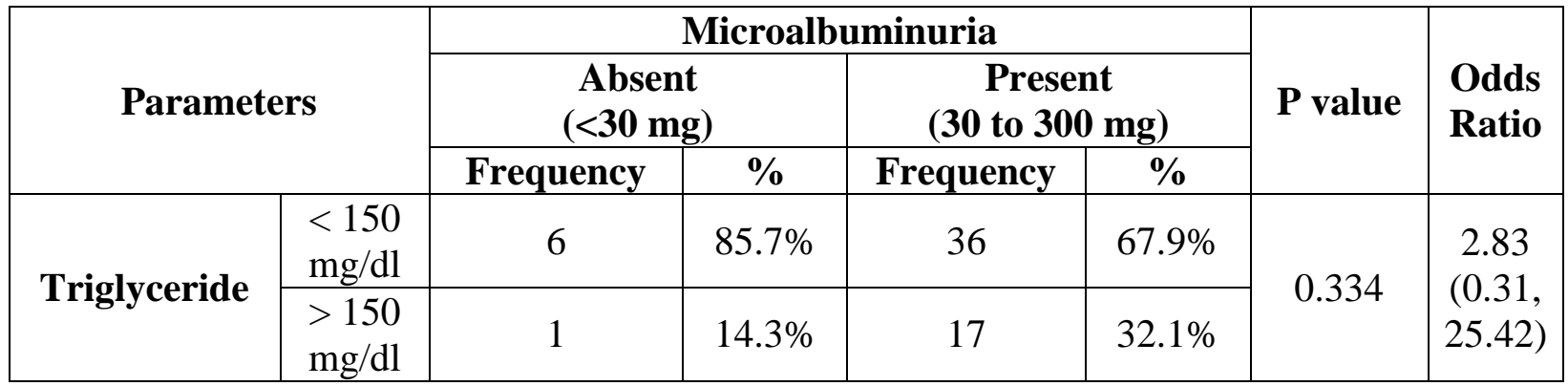

There was no significant association between HDL and Microalbuminuria among CAD subjects in the study. Odds ratio was 2.042, i.e. CAD subjects with HDL <40 in Females and $<50$ in males are at 2.042 times higher risk for Microalbuminuria than subjects with Normal HDL levels, but risk was not statistically significant (Table 17).
Table 18 shows that there was no significant association between LDL and Microalbuminuria among CAD subjects in the present study. Odds ratio was 0.76 , i.e. CAD subjects with $\mathrm{LDL}>150 \mathrm{mg} / \mathrm{dl}$ are at 0.76 time higher risk for Microalbuminuria than subjects with LDL $<150 \mathrm{mg} / \mathrm{dl}$, but risk was not statistically significant.

Table.17 Association between Microalbuminuria and HDL in CAD subjects

\begin{tabular}{|c|c|c|c|c|c|c|c|}
\hline \multirow{3}{*}{\multicolumn{2}{|c|}{ Parameters }} & \multicolumn{4}{|c|}{ Microalbuminuria } & \multirow{3}{*}{ P value } & \multirow{3}{*}{ Odds Ratio } \\
\hline & & \multicolumn{2}{|c|}{$\begin{array}{c}\text { Absent } \\
(<30 \mathrm{mg})\end{array}$} & \multicolumn{2}{|c|}{$\begin{array}{c}\text { Present } \\
\text { (30 to 300 mg) }\end{array}$} & & \\
\hline & & Frequency & $\%$ & Frequency & $\%$ & & \\
\hline \multirow{2}{*}{ HDL } & Abnormal & 6 & $85.7 \%$ & 49 & $92.5 \%$ & \multirow{2}{*}{0.544} & \multirow{2}{*}{$\begin{array}{c}2.042(0.19, \\
21.4)\end{array}$} \\
\hline & Normal & 1 & $14.3 \%$ & 4 & $7.5 \%$ & & \\
\hline
\end{tabular}

Table.18 Association between Microalbuminuria and LDL in CAD subjects

\begin{tabular}{|c|c|c|c|c|c|c|c|}
\hline \multirow{3}{*}{\multicolumn{2}{|c|}{ Parameters }} & \multicolumn{4}{|c|}{ Microalbuminuria } & \multirow{3}{*}{$P$ value } & \multirow{3}{*}{ Odds Ratio } \\
\hline & & \multicolumn{2}{|c|}{$\begin{array}{c}\text { Absent } \\
(<30 \mathrm{mg})\end{array}$} & \multicolumn{2}{|c|}{$\begin{array}{c}\text { Present } \\
\text { (30 to } 300 \mathrm{mg} \text { ) }\end{array}$} & & \\
\hline & & Frequency & $\%$ & Frequency & $\%$ & & \\
\hline \multirow{2}{*}{ LDL } & $<150 \mathrm{mg} / \mathrm{dl}$ & 6 & $85.7 \%$ & 47 & $88.7 \%$ & \multirow{2}{*}{0.818} & \multirow{2}{*}{$\begin{array}{c}0.76(0.07, \\
7.49)\end{array}$} \\
\hline & $>150 \mathrm{mg} / \mathrm{dl}$ & 1 & $14.3 \%$ & 6 & $11.3 \%$ & & \\
\hline
\end{tabular}

\section{Age distribution}

In this study majority of subjects were in the age group 51 to 60 yrs (40\%), followed by $>60$ years $(30 \%), 41$ to 50 years $(20 \%)$ and $<40$ years $(10 \%)$. This suggests that CAD is more common after 50 years of age. There was significant difference in proportions. The Mean age recorded in the present study was $55.13 \pm 9.95$ years which is very close the results of $56 \pm 8,55 \pm 13$ and $57 \pm 10.1$ years recorded by Hyo Eun Park et al., (2012), Diercks et al., (2000) and Donal et al., (1993) respectively. 


\section{Gender Distribution}

In this study majority of subjects were males $(78.3 \%)$ and rest were females $(21.7 \%)$. This observation was statistically significant $(\mathrm{p}<0.0001)$. Similarly in the following studies the prevalence is more among males. Similar studies in case of males have already been reported by Hilal et al., (2015) (76\%) Donal et al., (1993) (84\%) The above mentioned studies also showed the higher prevalence of CAD in males.

\section{Family history of CAD}

In our study, $66.7 \%$ of CAD subjects had family history of CAD. There was no significant association between Family H/O. CAD and Microalbuminuria among CAD subjects in the study. Odds ratio was 3.083, i.e. CAD subjects with Family history of CAD are at 3.083 time higher risk for Microalbuminuria than without Family H/O CAD. This observation is statistically significant. There is a variation among similar studies. The family history of CAD was 24.3, 30.7 and $65.0 \%$ as reported by Donal et al., (1993), Diercks et al., (2000) and Vida Nesar et al., (2009) respectively. Donal et al., obtained positive results of family history of CAD similar to present study, whereas Diercks et al., and Vida Nesar et al., couldn't obtain similar results.

\section{Smoking}

In this study $58.3 \%$ of subjects had history of smoking but there was no significant difference in proportions. There was significant association between Smoking and Microalbuminuria among CAD subjects in the study. Odds ratio was 10.74 , i.e. Smokers are at 10.74 time higher risk for Microalbuminuria than Nonsmokers, and this observation was highly statistically significant. Klausen et al., (2004) also reported very close results of 58\% smoking history among subjects. However, in a similar study, Dierecks et al., (2000) found lower smoking history of $47 \%$ among the subjects.

\section{BMI}

There was no significant association between BMI and Microalbuminuria among CAD subjects in the study. Odds ratio was 1.19, i.e. CAD subjects with BMI $>23$ are at 1.19 time higher risk for Microalbuminuria than subjects with BMI <23, but risk was not statistically significant. Similar results of BMI above 23.0 was also reported by Hyo Eun park et al., (2012), Klausen et al., (2004) and Dierecks et al., (2000).

\section{Hypertension}

In this study there was significant association between Hypertension and Microalbuminuria among CAD subjects in the study. $69.8 \%$ hypertensive subjects and $30.2 \%$ normotensive subjects had microalbuminuria. Odds ratio was 32.38 , i.e. Hypertensive subjects are at 32.38 time higher risk for Microalbuminuria than Non hypertensive subjects, and this observation was highly statistically significant.

Similar to the present study, Damsgaard et al., and Yudkin et al., demonstrated significant association between Hypertension and Microalbuminuria. But studies done by Klausen et al., and Hilal et al., couldn't confirm the significant association between the two. This study shows $30.2 \%$ of nondiabetic, non-hypertensive patients had significant microalbuminuria.

\section{Lipid Profile}

In my study there was no significant association between Total cholesterol and Microalbuminuria among CAD subjects in the study. Odds ratio was 0.44 , i.e. CAD subjects 
with Total cholesterol $<200 \mathrm{mg} / \mathrm{dl}$ were protected from Microalbuminuria than subjects with Total cholesterol > 200mg/dl, but it was not statistically significant.

There was no significant association between Triglyceride and Microalbuminuria among CAD subjects in the study. Odds ratio was 2.83 , i.e. CAD subjects with TGL $>150 \mathrm{mg} / \mathrm{dl}$ are at 2.83 times higher risk for Microalbuminuria than subjects with TGL < $150 \mathrm{mg} / \mathrm{dl}$, but risk was not statistically significant. There was no significant association between HDL and Microalbuminuria among CAD subjects in the study. Odds ratio was 2.042 , i.e. CAD subjects with HDL $<40$ in Females and $<50$ in males are at 2.042 time higher risk for Microalbuminuria than subjects with Normal HDL levels, but risk was not statistically significant.

There was no significant association between LDL and Microalbuminuria among CAD subjects in the study. Odds ratio was 0.76, i.e. CAD subjects with LDL > 150mg/dl are at 0.76 time higher risk for Microalbuminuria than subjects with LDL $<150 \mathrm{mg} / \mathrm{dl}$, but risk was not statistically significant.

In this study Total Cholesterol and all Lipid Fractions, had no statistical significanct association with microalbuminuria. Donal et al., (1993) Hilal et al., (2015) and Vida Nesar et al., (2009) also couldn't establish significant association between Cholesterol and Microalbuminuria in their studies.

\section{Microaluminuria and CAD}

Prevalence of Microalbuminuria among CAD patients without diabetes was $88.3 \%$. This observation was highly statistically significant ( $<<0.001)$. Mean Microalbumin levels was $56.9 \pm 30.4 \mathrm{mg}$. A cross sectional study done by Klausen, Knut Borch-Johnson et al., from the Centre of preventive medicine, Glostrup
University hospital, Glostrup Department of Nephrology Herlev hospital University Herlev, Denmark have concluded that microalbuminuria is not only an independent predictor of IHD but also substantially increases the risk associated with other established risk factors for coronary artery disease. In an another study Yudkin et al., in 1988 demonstrated that microalbuminuria was associated with 24 fold increased mortality in non diabetic individuals. In Danish Hospital a study done by Jensen. J.S, Feldt-Rasmusen concluded microalbuminuria as an independent risk factor for IHD among hypertensive individuals who are non diabetic.

In a study "Microalbuminuria in Non diabetic Adults and Relation of Blood Pressure, Body Mass Index, Plasma Cholesterol Levels, and Smoking":Gubbio population study for 1567 participants (677 men and 890 women) aged 45 to 64 without macroalbuminuria without diabetes, results showed blood pressure, plasma cholesterol levels, smoking and BMI significantly related to urinary albumin excretion and prevalence of microalbuminuria. The relative risk of Microalbuminuria with $18 \mathrm{mmHg}$ higher Systolic Blood Pressure in men and women was 2.5 and 1.62 respectively; with $40 \mathrm{mg} / \mathrm{dl}$ higher plasma cholesterol was 2.25 and 2.10 respectively; with smoking was 1.99 and 1.91 respectively; with $4 \mathrm{~kg} / \mathrm{m}^{2}$ higher BMI was 1.83 And 1.33 respectively.

In a study Hillege HR, Jannsen WM, conducted by department of Pharmacology Groningen, Netherlands postal questionnaire and a vial to collect on morning spot urine, were sent to 85421 subjects aged between 28 to 75. Cardiovascular risk factors and morbidity were validated in a well-defined non diabetic and non-hypertensive group of 5241 subjects. Microalbuminuria appears to be not only in general population but also in non- 
diabetic and non-hypertensive population and is independently associated with increased cardiovascular risk factors and cardiovascular morbidity.

It is concluded that this study recommends estimating Urinary Albumin excretion for 24 hours to identify high risk individuals for Coronary Artery Disease and to add this laboratory workup as a tool for Primary Prevention of CAD.

\section{References}

Agewall, S., Wikstrand, J., Ljungman, S., Fagerberg, B. 1997. Usefulness of microalbuminuria in predicting cardiovascular mortality in treated hypertensive men with and without diabetes mellitus. Risk Factor Intervention Study Group. Am. J. Cardiol., 80: 164-69.

Agewall, S., Persson, B., Samuelsson, O., Ljungman, S., Herlitz, H., Fagerberg, B. 1993. On behalf of The Risk Factor Intervention Study Group: Microalbuminuria in treated hypertensive men at high risk of coronary disease. $J$ Hypertens, 11:461-459

Agrawal, B., Berger, A., Wolf, K., Luft, F.C. 1996. Microalbuminuria screening by reagent strip predicts cardiovascular risk in hypertension. J. Hypertens., 14: 223-28.

Albuminuria and risk of cardiovascular events, death, and heart failure in diabetic and nondiabetic, JAMA, 286(4): 421-6.

API text book of medicine 10th edition. Cardiology section chapter -16-18 (p No 890-915,

Arnlov, J., Evans, J.C., Meigs, J.B., Wang, T.J., Fox, C.S., Levy, D., Benjamin, E.J., D.A. gostino, R.B., Vasan, R.S. 2005. Low-grade albuminuria and incidence of cardiovascular disease events in nonhypertensive and nondiabetic individuals: The Framingham Heart Study. Circulation, 112: 969-975.

Assmann, G., Cullen, P., Schulte, H. 2002. Simple scoring scheme for calculating the risk of acute coronary events based on the 10-year follow-up of the prospective cardiovascular Munster (PROCAM) study. Circulation, 105: 310-315.

Basdevant, A., Cassuto, D., Gibault, T., Raison, J., Guygrand, B. 1994. Microalbuminuria and body fat distribution in obese subjects. Int. J. Obes., 18: 806-811.

Beamer, N.B., Coull, B.M., Clark, W.M., Wynn, M. 1999. Microalbuminuria in ischemic stroke. Arch. Neurol., 56: 699-702.

Bennett, P.H., Haffner, S., Kasiske, B.L. Screening and management of microalbuminuria in patients with diabetes mellitus: recommendations to the Scientific Advisory Board of the National Kidney Foundation from a nadhoc committee of the Council on Diabetes mellitus of the National Kidney Foundation. Am. J. Kidney Dis., 25: 107-12.

Borch-Johnsen, K., Feldt-Rasmussen, B., Strandgaard, S., Schroll, M., Jensen, J.S. 1999. Urinary albumin excretion. An independent predictor of ischemic heart disease. Arterioscler. Thromb. Vasc. Biol., 19: 1992-97.

Brantsma, A.H., Bakker, S.J., Hillege, H.L., deZeeuw, D., deJong, P.E., Gansevoort, R.T. 2005. Urinary albumin excretion and its relation with C-reactive protein and the metabolic syndrome in the prediction of type 2 diabetes. Diabetes Care, 28: 25252530.

Damsgaard, E.M., Froland, A., Jorgensen, O.D. et al. 1990. Microalbuminuria as predictor of increased mortality in elderly people. $B M J$, 300: 297-300

Damsgaard, E.M., Mogensen, C.E. 199. Microalbuminuria as predictor of increased mortality in elderly people. $B M J, 300$ : $297-$ 300.

de Wardener, H.E. 1985. The Kidney. Edinburgh: Churchill Livingstone, 49-50.

de Zeeuw, D., Parving, H.H., Henning, R.H. 2006. Microalbuminuria as an early marker for cardiovascular disease. J. Am. Soc. Nephrol., 17: 2100-2105.

Deckert, T., Feldt-Rasmussen, B., Borch-Johnsen, K., et al. 1989. Albuminuria reflects widespread vascular damage. The Steno hypothesis. Diabetologia, 32: 219-226. 
Deckert, T., Kofoed-Enevoldsen, A., Norgaard, K., Borch-Johnsen, K., Feldt-Rasmussen, .B, Jensen, T. 1992. Microalbuminuria. Implications for micro- and macrovascular disease. Diabetes Care, 15: 1181-91

Deen, W.M., B.D., Brenner, B.M. 1982. The glomerular barrier to macromolecules: therotical and experimental considerations. In: Brenner BM, Stein JA, eds. Nephrotic Syndrome. New York: Churchill Livingstone, 8-9.

Diercks, G.F., Hillege, H.L., van Boven, A.J., Kors, J.A., Crijns, H.J., Grobbee DE, de Jong PE, van Gilst WH: Microalbuminuria modifies the mortality risk associated with electrocardiographic ST-T segment changes. J. Am. Coll. Cardiol., 40: 1401.

Diercks, G.F.H., van Boven, A.J., Hillege, H.L., et al. 2000. Microalbuminuria is independently associated with ischemic electrocardiographic abnormalities in a large non-diabetic population. The PREVEND (Prevention of Renal and Vascular ENdstage Disease) study. Eur Heart J., 21:1922-1927.

Donal Buggy, John Feely, John Murphy, Cathal O'Sullivan and Michael Walsh. 1993. Microalbuminuria and Coronary Heart Disease in Non-diabetics. Postgrad Med. J., 69(704-707).

Festa, AD,. Agostino, R., Howard, G., et al. 2000. Inflammation and microalbuminuria in nondiabetic and type 2 diabetic subjects: The Insulin Resistance Atherosclerosis Study. Kidney Int., 58: 1703-1710.

Forman, J.P., Brenner, B.M. 2006. Hypertension and microalbuminuria: the bell tolls for thee. Kidney Int., 69: 22-28.

Gerstein, H.C., Mann, J.F., Pogue, J. et al. 2000. Prevalence and determinants of microalbuminuria in high-risk diabetic and nondiabetic patients in the Heart Outcomes Prevention Evaluation Study. The HOPE Study Investigators. Diabetes Care, 23 (suppl 2): B35-39.

Gerstein, H.C., Mann, J.F., Yi, Q, et al. Microalbuminuria and risk of cardiovascular events, death, and heart failure in diabetic and nondiabetic individuals. JAMA, 286:421-426.
Gosling, P., Beevers, D.G. 1989. Urinary albumin excretion in the general population. Clin. Sci., 76: 39-42.

Gosling, P., Hughes, E.A., Reynolds, T.M., Fox, J.P. 1991. Microalbuminuria is an early response following acute myocardial infarction. Eur. Heart J., 12: 508-13.

Gosling, P. 1995. Microalbuminuria: a marker of systemic disease. Br. J. Hosp. Med., 54: 285-90.

Greenland, P., Knoll, M.D., Stamler, J. et al. 2003. Major risk factors as antecedents of fatal and nonfatal coronary heart disease events. JAMA, 290: 891-897.

Haffner, S.M., Stern, M.P., Gruber, M.K., Hazuda, H.P., Mitchell, B.D., Patterson JK. Microalbuminuria.Potential marker for increased cardiovascular risk factors in nondiabeticsubjects? Arteriosclerosis 1990; 10: 727-31.

Harrison's principles of internal medicine 19th edition.-volume II Chapter -264-266;291299 (p.No -1439-1441;1578-1630.

Hilal Bahjet al-Saffar, Hussein Nassir, Anna Mitchell and Sebastin Philipp. 2015. Microalbuminuria in non-diabetic patients with Unstable angina/ non ST-segment elevation Myocardial infraction. BMC Res Notes, 8: 371.

Hillege, H.L., Janssen, W.M., Bak, A.A., et al. 2001. Microalbuminuria is common, also in a nondiabetic, nonhypertensive population, and an independent indicator of cardiovascular risk factors and cardiovascular morbidity. J. Intern Med., 249: 519-526.

Hyo Eun Park, Nam Ju Heo. 2013. Significance of Microalbuminuria in Relation to Subclinical Coronary Atherosclerosis in Asymptomatic Nonhypertensive ,Nondiabetic Subjects. J. Korean Mes. Sci., 28: 409-414.

Jager, A., Kostense, P.J., Ruhe, H.G., Heine RJ, Nijpels G, Dekker JM, Bouter LM, Stehouwer CD: Microalbuminuria and peripheral arterial disease are independent predictors of cardiovascular and all-cause mortality, especially among hypertensive subjects: Five-year follow-up of the Hoorn Study. Arterioscler. Thromb. Vasc. Biol., 19: 617-624. 
Jensen, J.S., Borch-Johnsen, K., Feldt-Rasmussen, B., Appleyard, M., Jensen, G. 1997. Urinary albumin excretion and history of acute myocardial infarction in a crosssectional population study of 2,613 individuals. J. Cardiovasc. Risk, 121-25.

Jensen, J.S. 1995. Renal and systemic transvascular albumin leakage in severe atherosclerosis. Arterioscler. Thromb. Vasc. Biol., 15: 1324-29.

Jensen, J.S., Borch-Johnsen, K., Jensen, G., FeldtRasmussen, B: Microalbuminuria reflects a generalized transvascular albumin leakiness in clinically healthy subjects. Clin. Sci., 88: 629-633.

Jones, C.A., Francis, M.E., Eberhardt, M.S., Chavers B, Coresh J, Engelgau M, KusekJW, Byrd-Holt D, Narayan KM, Herman WH, Jones CP, Salive M, Agodoa LY: Microalbuminuria in the US population: Third National Health and Nutrition Examination Survey. Am. J. Kidney Dis., 39: 445-459.

Karalliedde, J., Viberti, G. Microalbuminuria and cardiovascular risk. Am. J. Hypertension, 17: 986-993.

Khot, U.N., Khot, M.B., Bajzer, C.T. et al. 2003. Prevalence of conventional risk factors in patients with coronary heart disease. JAMA, 290: 898-904.

Klausen, K., Borch-Johnsen, K., FeldtRasmussen, B., Jensen, G., Clausen, P., Scharling, H., Appleyard M, Jensen JS: Very low levels of microalbuminuria are associated with increased risk of coronary heart disease and death independently of renal function, hypertension, and diabetes. Circulation, 110: 32-35.

Knight, E.L., Kramer, H.M., Curhan, G.C. HighNormal Blood Pressure and Microalbuminuria. Am. J. Kidney Dis., 41: 588-595.

Krishnaveni, A., A.N.R. Lakshmi, Paramjyothi. Associate Professor of physiology, Professor and Head, Department Of Physiology, Assistant professor of physiology, Kakatiya Medical college, Warangal, Andhra Pradesh, India. Significance of Microalbuminuria in Metabolic syndrome International Journal of Biological \& Medical Research.
Kuusisto, J., Mykkanen, L., Pyorala K, Laakso M. Hyperinsulinemic microalbuminuria. A new risk indicator for coronary heart isease.Circulation, 91: 831-37.

Marcovina, S.M., Albers, J.J., Scanu, A.M. et al. 2000. Use of a reference material proposed by the International Federation of Clinical Chemistry and Laboratory Medicine to evaluate analytical methods for the determination of plasma lipoprotein(a). Clin. Chem., 46: 1956-1967.

Marcovina, S.M., Koschinsky, M.L., Albers, J.J., Skarlatos S. Report of the National Heart, Lung and Blood Institute Workshop on Lipoprotein (a) and Cardiovascular Disease: recent advances and future directions. Clin. Chem., 49: 1785-1796.

Mark, E. Molitch, Demetra Rupp, Mercedes Carnethon. Higher Levels of HDL Cholesterol are associated with a Decreased Likelihood of Albuminuria in patients with Long-Standing Type I Diabetes.Diabetes Care, Vol: 29: 1(78-82)

Massimo Cirillo, Luigi Senigalliesi, Martino Laurenzi et al. 1998. Microalbumimuria in Non-diabetic Adults: Relation of Blood Pressure, BMI, Plasma Cholesterol Levels and Smoking: The GUbbio Population. Arch. Intern. Med., 158(17):1933-1939.

Metcalf, P., Baker, J,. Scott, A., Wild, C., Scragg, $\mathrm{R}$, Dryson, E: Albuminuria in people at least 40 years old: Effect of obesity, hypertension and hyperlipidemia. Clin. Chem., 38: 1802-1808,

Mykkanen L, Zaccaro DJ, Wagenknecht LE, et al. Microalbuminuria is associated with insulin resistance in nondiabetic subjects: the insulin resistance atherosclerosis study. Diabetes, 47:793-800.

Ochodnick,y P., Henning, R.H., van Dokkum, R.P.E., deZeeuw, D. 2006. Microalbuminuria and endothelial dysfunction: Emerging targets for primary prevention of end-organ damage. J. Cardio vasc. Pharmacol., 47: S151-S162.

Omer Kozan, Emin Evren Ozcan, Oktay Sancaktar, Giray Kabakci. The Prevalrnce of Microalbuminuria and relevant cardiovascular risk factors in Turkish Hypertensive patients. Arch. Turk. Soc. Cardiol., 39(8): 635-645. 
Pedrinelli, R., Gianpietro, O., Carmassi, F., et al. 1994. Microalbuminuria and endothelial dysfunction in essential hypertension. Lancet, 344: 14-18.

Ritz, E. 2003. Albuminuria and vascular damageThe vicious Twins. New Eng. J. Med., 348: 2349-2352.

Romundstad, S., Holmen, .J, Kvenild, K., Hallan, H., Ellekjaer, H. 2003. Microalbuminuria and all-cause mortality in 2,089 apparently healthy individuals: A 4.4-year follow-up study. The Nord-Trondelag Health Study (HUNT), Norway. Am. J. Kidney Dis., 42: 466-473.

Ruggenenti, P., Remuzzi, G. 2006. Time to abandon microalbuminuria. Kidney Int., 70: 1214-1222.

Ruilope, L.M. \& Rodicio, J.L. 1996. Hypertension, atherosclerosis and microalbuminuria in ELSA Study. Blood Pressure, (Suppl 4):48-52,

Slowik, A., Turaj, W., Iskra, T., Strojny, J., Szczudlik, A. 2002. Microalbuminuria in nondiabetic patients with acute ischemic stroke: Prevalence, clinical correlates, and prognostic significance. Cerebrovasc. Dis., 14: $15-21$.

Stehouwer, C.D., Henry, R.M., Dekker, J.M., Nijpels, G., Heine, R.J., Bouter, L.M. 2004. Microalbuminuria is associated with impaired brachial artery, flow-mediated vasodilation in elderly individuals without and with diabetes: Further evidence for a link between microalbuminuria and endothelial dysfunction-The Hoorn Study. Kidney Int Suppl 92: S42-S44, 2004.

Stehouwer, D., Smulders, Y.M. 2006. Microalbuminuria and risk for cardiovascular disease: Analysis of potential mechanisms. J. Am. Soc. Nephrol., 17: 2106-2111.

Stuveling, E.M., Hillege, H.L., Bakker, S.J., Asselbergs, F.W., de Jong, P.E., Gans, R.O., de Zeeuw, D. PREVEND study group: C-reactive protein and microalbuminuria differ in their associations with various domains of vascular disease. Atherosclerosis 172: 107114.

The Relationship of Microalbuminuria with Metabolic Syndrome Hyo Sun Choi, Seung
Ho Ryu, Kyu-Beck LeeDivision of Nephrology and Occupational Medicine, Sungkyunkwan University, School of Medicine, Kangbuk Samsung Hospital, Seoul, Korea.

Tuttle, K.R., Puhlman, M.E., Cooney SK, Short $\mathrm{R}$ : Urinary albumin and insulin as predictors of coronary artery disease: An angiographic study. Am. J. Kidney Dis., 34: 918-925.

Viberti, G.C., Hill, R.D., Jarrett, R.J., Argyropoulos, A., Mahmudu, Keen, H. 1982. Microalbuminuria as a predictor of clinical nephropathy in insulin-dependent diabetes mellitus, Lancet, 1: 1430-32.

Vida Nesar Hoseini, Mehdi Rasouli. Microalbuminuria correlates with the prevalence and severity of coronary artery disease in non-diabetic patients. Cardiology J., Vol. 16, No.2(142-145)

Voss, R., Cullen, P., Schulte, H., Assmann, G. 2002. Prediction of risk of coronary events in middle- aged men in the Prospective Cardiovascular Munster Study(PROCAM) using neural net works. Int. J. Epidemiol., 31:1253-1262

Wachtell, K., Palmieri, V., Olsen, .M.H, Bella, J.N., Aalto, T., Dahlof, B., Gerdts, E, Wright JT Jr, Papademetriou V, Mogensen CE, Borch-Johnsen K, Ibsen H, Devereux RB: Urine albumin/ creatinine ratio and echocardiographic left ventricular structure and function in hypertensive patients with electrocardiographic left ventricular hypertrophy: The LIFE study. Losartan Intervention for Endpoint Reduction. Am. Heart J., 143: 319-326.

Wilson, P.W., D.A. Gostino, R.B., Levy, D., Belanger, A.M., Silbershatz, H., Kannel, W.B. 2998. Prediction of coronary heart disease using risk factor categories. Circulation, 97: 1837-1847.

Winocour, P.H., Harland, J.O.E., Millar, J.P., Laker, M.F., Alberti, K.G.M.M. 1992. Microalbuminuria and associated cardiovascular risk factors in the community. Atherosclerosis, 93: 71-81.

Yasar Yildrum, Zulfukar Yilmaz, Elif Anik et al. 2014. The Evaluation of relationship between Microalbuminuria Frequency and Life Style Parameters in Non-Diabetic 
Prehypertensive Patients. Int. Arch. Med. Res., Volume 6, No.1,pp.5-16.

Yudkin, J.S., Forrest, R.D., Jackson, C.A. 1988. Microalbuminuria as predictor of vascular disease in non-diabetic subjects. Islington Survey. Lancet, ii: 530-33.

Yuyun, M.F., Khaw, K.T., Luben, R., Welch, A., Bingham, S., Day, N.E., Wareham, N.J.
2004. Microalbuminuria independently predicts all-cause and cardiovascular mortality in a British population: The European Prospective Investigation into Cancer in Norfolk (EPIC-Norfolk) population study. Int. J. Epidemiol., 33: 189-198.

\section{How to cite this article:}

Sunjay Pradhep, R.L., N. Janakiram, Vivek Paul Benjamin and Natarajan, S. 2017. A Study of Microalbuminuria in Coronary Artery Disease among Non-Diabetic Individuals. Int.J.Curr.Microbiol.App.Sci. 6(1): 344-361. doi: http://dx.doi.org/10.20546/ijcmas.2017.601.042 